\title{
Studying Annulment Actions
}

In the remainder of this book, we study the sequence through which annulment litigation affects multilevel politics. This sequence is composed of distinct, yet interlinked, analytical steps that feed into each other. We start by (1) analysing actors' motivations for turning a policy controversy into a judicial conflict. From there, we move on to investigate (2) litigant configurations that influence annulment proceedings, all the way to assessing (3) the judicial outcome and the political and institutional impact of annulment actions. Our focus on this whole sequence reflects our presumption that there are several different things to analyse in order to understand how the emergence of annulment litigation feeds back into the European Union (EU) multilevel system. We have to understand when and why different kinds of actors want to initiate annulment litigation; how this intention by different actors is reflected by the litigant configuration in court; and how this litigant configuration relates to judicial behaviour. Finally, we have to understand the institutional and political effects of judgements. Focusing on this whole sequence sets this book apart from much of the extant research on legal conflicts in the EU multilevel system, which has typically focused on these steps individually, without conceiving them as elements coming together in the form of a complex process. The research design applied in this study is thus innovative as it attempts to combine the analysis of single steps individually with a systematic argument about their interlinkages and their respective roles in the broader sequence through which litigation intervenes in multilevel governance.

(C) The Author(s) 2020

C. Adam et al., Taking the EU to Court, Palgrave Studies in European Union Politics, https://doi.org/10.1007/978-3-030-21629-0_4 
In terms of data, this project brings together original quantitative data that aggregates information based on court documents on annulment actions as well as qualitative data collected through interviews with actors that took part in the studied processes and available documents. For each step of this study, we are thus able to combine quantitative analysis with in-depth analysis of concrete EU annulment conflicts. We also bring together a broad range of mostly new data sources, notably forty expert interviews with actors involved in annulment conflicts at the different stages of the EU multilevel system and a large- $\mathrm{N}$ original data set on all annulment actions in the EU multilevel system. Most of the annulment actions analysed in our case studies date from the last ten years. This relative recentness allows tracing processes that are still relatively fresh in the memories of interviewees. The data set, in contrast, allows us to assess long-term trends and to reach much further back in time. Specifically, it covers the whole period from the Treaties of Rome to the end of 2012. Specifically, we include annulment actions that obtained a judgement until the end of 2015. Note that once an annulment action is launched, it takes on average twenty-four months-at times substantially longer-until a judgement is taken. Thus, our quantitative analysis captures cases that have been launched until 2012 and concluded at the end of 2015. We can thus draw upon different quantitative and qualitative analysis techniques to shed light on the chain through which annulment conflicts intervene in the EU multilevel system. This chapter explains the logic behind the choice of our research strategy in more detail and justifies our case selection. Moreover, it provides all necessary information about the empirical material we collected. We hope that this chapter allows the reader to assess the empirical and systematic quality of our subsequent arguments and claims.

\section{Research STRATEgy}

So far, political science has paid little attention to annulment conflicts in the EU as an analytical category of its own. In fact, doing so begs the question of how the study of annulment actions can improve our understanding of EU multilevel politics. What are these annulment actions? To which theoretical concepts do they relate? Are they a case of supranational noncompliance and implementation conflict in the EU that could bring a new dimension to research on compliance and implementation? Will they help us to study this phenomenon of supranational 
noncompliance, or are actions for annulment only a tool of inter-institutional conflict and procedural politics, which help EU institutions struggle for legislative influence (Jupille 2004)? Do they speak to research on the strategic interaction between these institutions in the process of legislative bargaining, or are actions for annulment merely another channel through which the Court can influence the trajectory of European integration by means of judicial law making? Are they thus mainly a category of cases able to speak to scholars of judicial behaviour and European integration who have so far focussed primarily on the role of preliminary references?

Our tentative answer to all of these questions is yes. Actions for annulment are probably best viewed as a case of all of these things. Therefore, in order to understand their political role, all of these aspects have to be taken into account at the same time. Therefore, we take a more general approach and treat annulment actions as manifestations of conflict within the EU's multilevel system. These conflicts manifest themselves as accusations of noncompliance against EU institutions. Yet often, they result from conflicts over policy application between the respective supranational institution and national actors. As a result of these conflicts, the Court is activated and obtains a chance to develop the rules guiding policy making and decision competences within the multilevel system. All of these different aspects can be integrated by considering annulment actions as manifestations of conflicts within the multilevel system that are judicialised and thereby enabled to leave a permanent mark in that multilevel system. Therefore, it is essential to adopt a sequential analytical perspective that is able to integrate the individual steps within this rather complex chain of events that define the role and impact of annulment litigation. Because of the complexity of such an endeavour and the rather limited insights of prior research on the political role of annulments, such an effort is necessarily explorative to some extent.

With regard to the sequential causal chain linking litigation to multilevel governance, our research design is informed by the limited availability of data and theory that would allow tracing the conceptualized causal chain from the beginning to the end of an annulment cycle. Information on annulment conflicts seldom starts with the motivations underlying the conflict or ends with how rulings feed back into policy making. Given the absence of existing data covering all relevant steps of the chain, in combination with the lack of systematic theorizing about the operating causal mechanisms, our endeavour has an important exploratory 
dimension, which speaks for a deductive-inductive strategy carried out by a mixed methods approach. The analysis of the relevant steps in the annulment sequence (motivations to litigate, litigants' constellations, ruling outcomes, ruling impact) thus constitutes a heuristic attempt to order our research field and allow for applying theoretical insights from other discussions. Case study evidence exemplifies the working of hypothesized causality empirically while at the same time bringing to the fore additional explanatory factors and mechanisms. Furthermore, quantitative analysis allows probing the plausibility (or even testing their fit) of these factors and mechanisms on a larger number of cases.

In terms of analytical framework, we combine a focus on each of the steps in the sequential causal chain individually with a comprehensive and synthetic approach of their linkage throughout the multilevel system. This way, characteristics carved out in earlier steps become explanations for patterns in later steps of the annulment sequence. We thus emphasize the endogenous character of the way litigation emerges from and intervenes in multilevel policy conflicts. To be clear, the research design does not focus exclusively on these endogenous factors shaping annulment conflicts in the multilevel system. Rather, while our sequential argument works out this endogenous causality for each step, it comes as a complement to broader explanations that also include exogenous factors.

In sum, since the existing literature (on other forms of EU litigation than annulments) frequently addresses the use of litigation, litigants' constellations, outcomes, and impact of litigation as analytically separated issues, they do so with an exogenous explanatory approach. By linking these steps together into a wider causal chain, we develop a new explanatory approach for annulment litigation that is based on endogenous mechanisms.

\section{Case Selection}

There have been several thousand annulment rulings since the founding of the EU in 1957. From this universe of cases, a number of annulment rulings were selected for in-depth analysis. We selected these annulments in order to cover both vertical and horizontal conflict categories.

With respect to vertical conflicts, the case selection proceeded in two steps, aiming to cover the widest possible variety of types of multilevel policy conflicts. In the first step, we selected two countries from which to choose annulment cases, namely Spain and Germany. We chose these 
countries for three reasons. First, both Spain and Germany are among the member states that raise most annulment actions per year (Bauer and Hartlapp 2010). Second, both countries present different litigant profiles, as shown by the different extent to which they raise preliminary rulings before the Court of Justice of the European Union (CJEU); Germany raises many, Spain relatively few. Third, most annulment actions raised by Spain relate to financial sanctions in EU redistributive policies, mainly in agriculture and cohesion policies; such cases related to fiscal issues are relatively rare in Germany. In other words, because of such structural differences between both member states, we have reason to suspect that the nature of the conflicts underlying litigation might differ in those countries, too.

In the second step, we chose a series of annulment cases in each country. To select those individual annulment cases, we started by listing for both countries all annulment actions raised by national or regional governments between 2010 and 2015, coding them with regard to the type of policy field they belong to and the subject of the dispute. Many of the cases dealt with conflicts over EU redistributive policies, as mentioned above in agriculture and cohesion policies. This seems to be a relatively homogeneous category of cases that focuses almost exclusively on financial issues (Bauer and Hartlapp 2010). To assure variance across cases, we decided to treat all cases related to the use of EU funds as one analytical category instead of picking individual cases within this policy field. We then randomly selected six cases in Spain and six cases in Germany among the remaining cases that did not fall into the EU redistributive category.

The selection of our horizontal annulment cases for in-depth study had to be done differently. First, because the conflict involved EU institutions on both sides of the conflict, no different polity contexts (i.e. member states) could be selected. All horizontal conflicts, by our definition, originate in the political system of the EU. To select a broad range of annulment cases involving European institutions, we thus looked at the cross-sectoral distribution of the full sample of horizontal cases. Distribution across policy fields was assessed via the treaty article(s) referred to in the ruling. Treaty articles were grouped into broader policy areas with the help of an established codebook (Stone Sweet and Brunell 1999). ${ }^{1}$ That meant, for example, that for external affairs, we selected all cases coded as dealing with external relations in the Stone Sweet and Brunell database (matter 412). ${ }^{2}$ Cases dealing with common 
and foreign security policy (matter 384), development cooperation (matters 338 and 419), or integrated Mediterranean programmes (matter 423 ) were added. Where multiple treaty bases applied without corresponding to the same policy area systematic, the substance of the case was assessed in detail to identify the dominant policy field, and the case was then accordingly assigned to the correct category.

It turned out that the category of external affairs is the area with the highest number of horizontal annulment conflicts (forty-one cases representing $29 \%$ of all cases). The second most important area is staff regulation and institutional provisions (twenty-two cases, or 15\%), followed by environment and energy as well as justice and home affairs (fourteen cases each, with the latter seeing a substantial hike in the last three years), agriculture and fisheries (eleven cases), community budget, state aid (eight cases each), and taxes (six cases). The number of horizontal annulment conflicts is negligible in all other policy fields (Hartlapp 2018). Based on this cross-policy distribution, we decided to focus on external affairs as the area with the highest overall number of annulment cases. Here, all cases have been studied systematically and in depth. In addition, horizontal cases from other policy areas have been added to the sample of cases studied in more depth where primary or secondary sources had highlighted that they are of particular interest, for example where interviewees mentioned them as particularly interesting or where a precedent was set. This helped us to gain in-depth insight into the most dynamic policy field while at the same time covering the politically relevant cases on other areas as well. In sum, our cases were selected to represent annulment conflicts that seem to be most typical from a bird's eye perspective while using the advantage of our research design to be open to include additional information and thus cases promising to enrich our understanding (see also Bauer and Knill 2014).

\section{DATA}

We built a data set covering all annulment actions that were launched since the founding of the European Community and received a judgement until the end of 2015. To this aim, we extracted all cases from the Stone Sweet and Brunell (2007) Data Set on Actions under Article 230: 1954-2006. We updated the selection done by our colleagues by retrieving the relevant information from CURIA and EurLex. All entries were double-checked and completed. We inserted in the emerging data base 
information on the date of litigation and ruling, claimant and defendant, the legal domain, or subject matter and decision type-thereby following and relying on Stone Sweet and Brunell's method. In addition, however, we added information on the title and substance of the case, the official number, actors intervening in the case, and information on who won or lost the case (here, cost transfer was used as indicator). In other words, we substantially enriched the Stone Sweet and Brunell database in terms of content and time line.

The database on which this book relies is substantially improved also with respect to data analysis done over the past years by us for various publications. First, we had selected only cases launched against the Commission (up until 2012); we later include actions against all EU institutions and not just against the Commission (until 2015). This includes the horizontal cases in which EU institutions also act as litigants. Additionally, this includes vertical cases in which the defendant is not the Commission (e.g. private/regional/member states v. Council/European Parliament [EP]/European Central Bank). This means that our analysis is no longer limited to accusations of noncompliance voiced against the Commission, but involves such actions raised against all EU institutions. Most importantly, however, we are able to assess the participant structure within these conflicts. We capture all litigants as well as all intervening parties for all of those cases. In our final database, every case refers to a factual court ruling. A ruling may combine court cases, and there can be more than one claimant to a case (joint cases). We treat joint cases as individual annulment conflicts as they result from the same underlying conflict. We include all cases initiated. Where cases were at some point found to be inadmissible, we record this as the respective judicial outcome of the conflict.

For the case studies, we meticulously analysed the text of the respective rulings and put it into context with other primary and secondary sources. Where access to primary documentation was restricted, we relied on expert interviews as the adequate approach to maximize the amount of available information for studying underlying motivations and assessments (e.g. Aberbach and Rockman 2002; Berry 2002). Our interviewees were usually high officials at the national level and EU level who themselves, in the capacity of their respective offices, took part in the decisions to litigate in the cases selected. Most of the time, our interviewees were state attorneys and officials from policy departments 
and legal services from the national and subnational ministries and EU institutions.

A total of forty semi-structured interviews were carried out between April 2009 and June 2016 in Berlin, Bilbao, Bonn, Brussels, Dresden, Madrid, Munich, and Santiago de Compostella (see the Annex for details). Three interview partners were Commission officials (labelled as COM_1, COM_2, COM_3), one interview partner worked in the legal service of the EP (EP_l), one interviewee came from the Council (CONS_1), nine interviewees worked for various German federal ministries (MIN_DE_l, etc.), nine interviewees were Spanish civil servants affiliated with various national ministries (MIN_ES_1, etc.), one interviewee worked for the regional ministry of Saxony (MIN_SA_1), one interviewee was from the regional ministry of Bavaria (MIN_BA_l), six interviewees were from various regional ministries of Galicia (MIN_ GA_l, etc.), five interviews were led with lawyers working in private law firms (LAW_l, etc.) and four interviews with employees from private or public companies involved in annulment litigation (COMP_l, etc.). ${ }^{3}$

Each of the interviews followed a semi-structured guideline with open questions and lasted between thirty minutes and two hours. ${ }^{4}$ The questions were constructed with a view to capturing process and preference information on the specific annulment cases as well as assessments of how specific the case at hand was-from the view of the interviewee-for EU annulment conflict more generally. In other words, we asked the interviewees to reconstruct the decision-making process of litigation and asked a series of questions aimed at uncovering the criteria and considerations that had driven the decision to litigate. All interviews were transcribed and deductively coded, which allowed systematic searches for specific issues covered throughout the argumentative chain; for example, to facilitate the interpretation of how the cases relate to motivations, we were interested in quotes that mentioned the objectives of going to court.

Besides collecting the interview material, we also traced information on the litigation process on the basis of published primary documents, most importantly the rulings and opinions available on CURIA. Apart from containing the CJEU's assessment of the situation, these documents typically describe the interaction between claimant and defendants in the conflict prior to litigation, as well as the core legal pleas brought forward. This information was complemented and validated by publicly available sources such as local, regional, and national press coverage and other media as well as position papers from the involved parties (when available). 


\section{Conclusion}

To sum up, in this chapter, we presented the reasons behind our choices about how to study EU annulment conflicts empirically. The sequential approach, which we deem necessary to capture the political role of actions for annulment, requires us to look into a variety of issues spanning from multilevel policy conflicts to the feedback effect of litigation into policies and institutions of the EU multilevel system. Our attempt to do justice to the complexity of our research object finds expression in the research design that covers different steps in the process individually and their chain-like relationship. We believe a combination of quantitative data analysis and studying selected cases in depth to be the most appropriate strategy. The efforts to collect this quantitative and qualitative data have been immense. As a result of these efforts, the subsequent chapters can rely on substantial and original empirical data.

\section{Notes}

1. We updated the codebook by Stone Sweet and Brunell in order to cover new treaty bases (1999).

2. The mentioned matters $412,338,384$, etc., are definitions taken from the codebook of Stone Sweet and Brunell (1999).

3. Please note that many of our interview partners were procedural and legal experts who spent much of their professional lives with annulments litigation. During the interviews, they added much to our understanding of various annulment cases.

4. Further details are provided in the Annex of this book.

\section{REFERENCES}

Aberbach, J. D., \& Rockman, B. A. (2002). Conducting and coding elite interviews. Political Science and Politics, 35, 673-676.

Bauer, M. W., \& Hartlapp, M. (2010). Much ado about money and how to spend it! Analysing 40 years of annulment cases against the European Union Commission. European Journal of Political Research, 49, 202-222.

Bauer, M. W., \& Knill, C. (2014). A conceptual framework for the comparative analysis of policy change: Measurement, explanation, and strategies of policy dismantling. Journal of Comparative Policy Analysis: Research and Practice, $16(3), 28-44$. 
Berry, J. M. (2002). Validity and reliability issues in elite interviewing. Political Science and Politics, 35, 679-682.

Hartlapp, M. (2018). Power shifts via the judicial arena: How annulments cases between EU institutions shape competence allocation. Journal of Common Market Studies, 56(6), 1429-1445.

Jupille, J. (2004). Procedural politics: Issues, influence, and institutional choice in the European Union. Cambridge, UK: Cambridge University Press.

Stone Sweet, A., \& Brunell, T. L. (1999). Data set on preliminary references in EC law. San Domenico di Fiesole, Italy: Robert Schuman Centre, European University Institute.

Stone Sweet, A., \& Brunell, T. L. (2007). Data set on actions under Article 230: 1954-2006. NEWGOV Project. San Domenico di Fiesole, Italy: Robert Schuman Centre, European University Institute.

Open Access This chapter is licensed under the terms of the Creative Commons Attribution 4.0 International License (http://creativecommons.org/licenses/ by $/ 4.0 /$ ), which permits use, sharing, adaptation, distribution and reproduction in any medium or format, as long as you give appropriate credit to the original author(s) and the source, provide a link to the Creative Commons license and indicate if changes were made.

The images or other third party material in this chapter are included in the chapter's Creative Commons license, unless indicated otherwise in a credit line to the material. If material is not included in the chapter's Creative Commons license and your intended use is not permitted by statutory regulation or exceeds the permitted use, you will need to obtain permission directly from the copyright holder. 